\title{
Interval Confinement in Compression Zone to Evaluated Beams Performance Subjected Monotonic Loads
}

\author{
Yulita Arni Priastiwi ${ }^{1, *}$, Iswandi Imran $^{2}$, Nuroji ${ }^{1}$, and Rudi Yuniarto Adi ${ }^{1}$ \\ ${ }^{1}$ Civil Engineering Department, Faculty of Engineering, Diponegoro University, Semarang, Indonesia \\ ${ }^{2}$ Structural Engineering Research Group, Civil Engineering Department, Bandung Institute of \\ Technology, Bandung, Indonesia
}

\begin{abstract}
Confinement is one way that can be used to improve the performance of reinforced concrete structures, mainly related to ductility. The parameter of the distance between the confinement becomes an important thing that must be studied its effect on ductility produced by a structural element. This study aims to study the effect of different distance between the confinement in compression zone in the beam at the plastic hinge area to the displacement and the behavior of the beam when it was given monotonic loading. The specimen model which is a simplified form of the plastic hinge area up front column will be fitted with a confinement in the compression zone which is attached to the shear reinforcement with different distances of $0,70,125 \mathrm{~mm}$. Also made a beam with a crossties confinement spaced $125 \mathrm{~mm}$ for comparison. The presence of a centralized load in the middle of the span is intended to obtain the largest moment and shear areas in the plastic hinge. The test results showed that the installation of $125 \mathrm{~mm}$ intervals for confinement in the compression zone resulted in a higher ductility of $11-18 \%$ against the beam without confinement than the $70 \mathrm{~mm}$ interval which only increased by $2.78 \%$. The hoops confinement produces higher ductility than crossties confinement for the same confinement interval. The increased confinement interval from 70 to 125 $\mathrm{mm}$ not yet significantly affect the moment capacity of the beam and the collapse was still dominant in the bending collapse although the distance between the stirrups and the confinement was slightly widened.
\end{abstract}

\section{Introduction}

Confinement is one way that can be used to improve the ductility of a reinforced concrete structure element [1]. Concrete with good and adequate confinement will be ductile and be high deformability especially in the post-elastic range [2]. Some research results indicate that the strength and ductility of reinforced concrete structural elements especially in the

\footnotetext{
* Corresponding author: yulita tiwi@ymail.com
} 
column are closely related to the lateral strain given by the stirrups with the spaced reinforcement as one of the determinants.

The distance of the stirrup will increase the unconfined volume of concrete and the possibility of spalling [4]. Minimum transverse reinforcement requirements are performed to avoid loss of power in case of spalling [5], and the presence of more tightly spaced restraint may increase the energy absorption rate of the column due to lateral loads gave [6].

This study aims to study the behavior of the plastic hinge beam area given confinement in the compression zone and mounted attached to stirrup for a backstop of shear. Different intervals between confinements are the parameters to be studied for their effect on the ductility of the plastic hinge region of the beam when given monotonic loading.

\section{Methods}

Four half-full scale specimens of the beam with size 150 × 300 × $4000 \mathrm{~mm}$ were made. The beam was given magnification in the middle of the span was called stub to obtain a simplified form of the plastic hinge area in the beam on the face of the column. The designs on the three specimens apart from the longitudinal reinforcement and stirrup for a backstop of shear also added confinement in compression zone of the beam. Confinement shaped hoops as well as crossties are entirely in compression zone of the beam and mounted attached to the stirrup. Confinement spacing is based on the distance needs of the shear stirrups for specimens without confinement $(\mathrm{s}=70 \mathrm{~mm})$ and widened for other specimens. The design of the specimen beam is shown in Fig. 1 and Fig. 2, while for the calculation of the spacing of the stirrups according to the prevailing standards in Indonesia [7], where the shear at the plastic hinge location is calculated based on the strongest possible moment value of the largest endpoint at the site and the distance between the stirrups according to the requirements specified for the plastic hinge area in order to avoid shear failure of the beam.

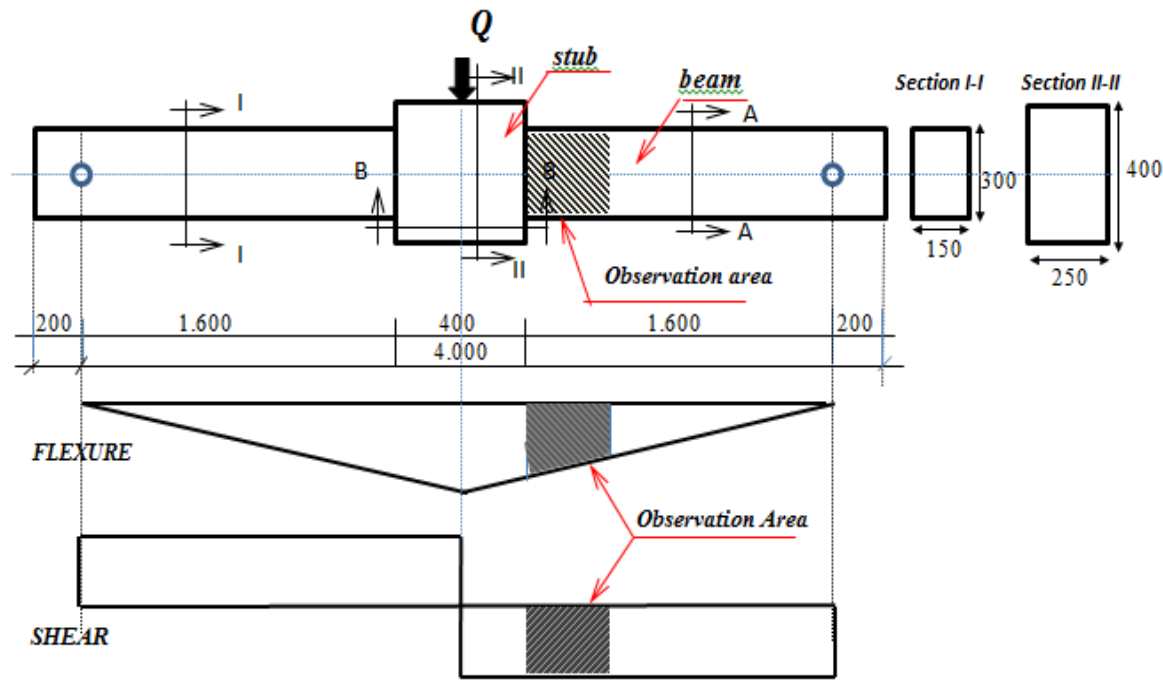

Fig. 1. Area Observation of Specimen 


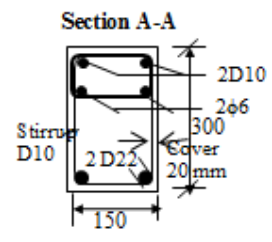

HOOPS CONFINEMENT DETAIL

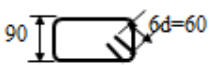

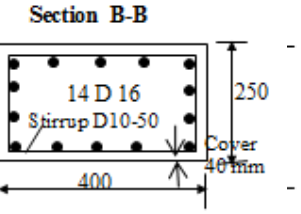

Section A-A

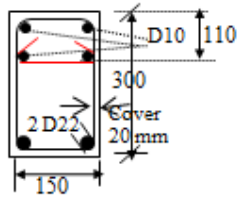

CROSSTIES CONFINEMENT DETAIL

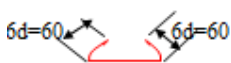

Fig. 2. The Section of Specimen

The calculation of shear reinforcement distance for beam without confinement using Eq. (1)

$$
s=\frac{A_{v} \cdot f_{y} \cdot d}{V_{s}}
$$

where $s=$ the spacing of stirrup, $A v=$ the area of leg stirrup, $f_{y}=$ the yield of reinforcement, $\mathrm{d}=$ the effective height of the beam, and $V_{s}=$ nominal shear force provided by shear reinforcement.

\subsection{Detail of Specimens}

All specimens in this study were designed with $25 \mathrm{MPa}$ concrete quality with a maximum aggregate of $10 \mathrm{~mm}$ with the intention that the aggregate granules can enter the sidelines of reinforcement so that the concrete is not porous. The specimens use the deform reinforcement for either the main longitudinal reinforcement, stirrup and the confinement reinforcement, whereas the additional longitudinal reinforcement used to $\phi 6 \mathrm{~mm}$ plain reinforcement.

The tensile reinforcement was used 2D22 $\left(f_{y}=476 \mathrm{MPa}\right)$, and the compressive reinforcement used $2 \mathrm{D} 10\left(f_{y}=444 \mathrm{MPa}\right)$. For the stirrup and confinement was used the reinforcement $\mathrm{D} 10\left(f_{y}=444 \mathrm{MPa}\right)$. At the magnification of the beam called the stub, it is installed 14D16 $\left(f_{y}=402 \mathrm{MPa}\right)$, while the additional reinforcement is used $2 \phi 6$ has $f_{y}=430$ $\mathrm{MPa}$. The distance of the shear stirrup $(s)$ based on the calculation for the beam without confinement in the plastic hinge area was $70 \mathrm{~mm}$, which is then made the minimum distance for the placement of the stirrups as well as the distance between the confinement $\left(s_{c}\right)$ of the specimen (BN and BC-70), while other specimens are obtained by how to widen the minimum distance. The specimen details are shown in Fig. 3 and Table 1.

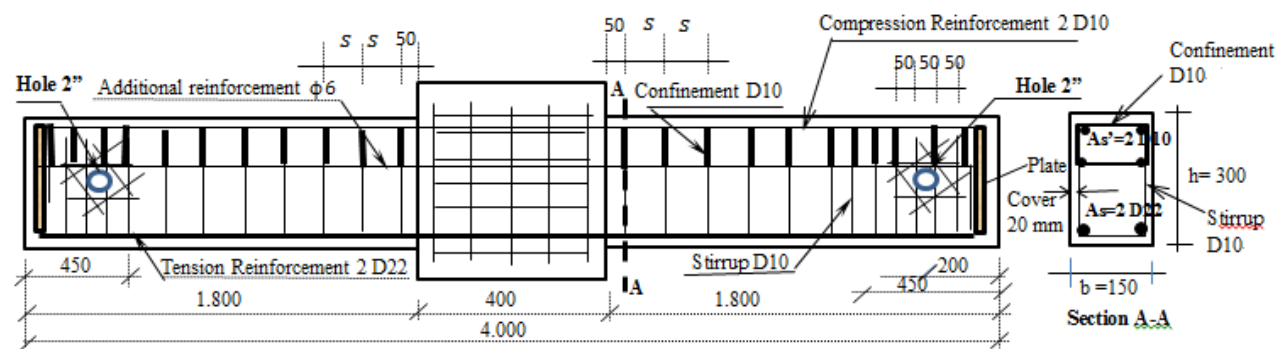

Fig. 3. Reinforcement in Specimen 
Table 1. Detail of Specimens

\begin{tabular}{|l|c|c|c|c|}
\hline Type & $\begin{array}{c}\mathbf{\rho} \\
(\mathbf{\%})\end{array}$ & $\begin{array}{c}\mathbf{\rho} \\
(\mathbf{\%})\end{array}$ & $\begin{array}{c}\boldsymbol{s} \\
(\mathbf{m m})\end{array}$ & $\begin{array}{c}\boldsymbol{s}_{\boldsymbol{c}} \\
(\mathbf{m m})\end{array}$ \\
\hline $\mathrm{BN}$ & 1.72 & 0.40 & 70 & 0 \\
\hline $\mathrm{BC}-70$ & 1.72 & 0.40 & 70 & 70 \\
\hline $\mathrm{BC}-125$ & 1.72 & 0.40 & 125 & 125 \\
\hline $\mathrm{BK}-125$ & 1.72 & 0.40 & 125 & 125 \\
\hline
\end{tabular}

\subsection{The Experimental Set up}

The specimens are placed on the loading frame with support by joints and rolls. The support was placed at the point as high beam of $200 \mathrm{~m}$ from each edge of the beam-free end. A $500 \mathrm{kN}$ hydraulic jack and load cell of similar capacity is used to provide central loading at the center of the beam span. The test was carried out with monotonic loading given in two loading stages: load control system and continued with displacement control system. The load control system was provided at 0.2 -ton intervals until loading is approximately $75 \%$ of the maximum theoretical calculation load and continued with the displacement control system until the ultimate condition of the beam is reached.

A Linear Variables Displacement Transducers (LVDT) was installed in the middle of the span to measure the deflection due to a given load. The resulting loading and displacement data will be recorded in the data logger to be processed and analyzed. In addition, LVDT was also installed in the horizontal direction on the top and bottom of the beam to measure the rotation that occurs. In the longitudinal reinforcement or concrete was also installed strain gauge to measure the strain that occurs due to loading. All data will be recorded in the data logger and will be analyzed until the moment-deflection relationship graph was obtained, while the strain information will be used to measure the magnitude of the curvature-moment in the beam specimens. In the curvature equation, the compressive strain on the concrete $\left(\varepsilon_{c}\right)$ and the tensile strain on the reinforcing steel $\left(\varepsilon_{s}\right)$ will be used and the curvature calculated according to Eq. 2 with $d$ is the distance between the two strains. The test set up refers to the research of Yulita et al [8].

$$
\varphi=\frac{\varepsilon_{c}+\varepsilon_{s}}{d}
$$

\section{Result and Discussion}

\subsection{Moment-Displacement Respons}

The test results in the load capacity $(\mathrm{kN})$ which is then changed in the moment capacity $(\mathrm{kN}-\mathrm{m})$ in the cross-section illustrated with the displacement in Fig. 4 and also in Table 2.

Table 2. Moment and ductility of specimens

\begin{tabular}{|c|c|c|c|c|c|c|c|c|}
\hline Specimen & $\begin{array}{c}\mathbf{M}_{\mathbf{u}} \\
(\mathbf{k N})\end{array}$ & $\begin{array}{c}\mathbf{M}_{\mathbf{y}} \\
(\mathbf{k N})\end{array}$ & $\begin{array}{c}\boldsymbol{\delta}_{\mathbf{y}} \\
(\mathbf{m m})\end{array}$ & $\begin{array}{c}\mathbf{D}_{\mathbf{r y}} \\
(\mathbf{\%})\end{array}$ & $\begin{array}{c}\boldsymbol{K}_{\boldsymbol{e}} \\
=\mathbf{M}_{\mathbf{v}} / \boldsymbol{\delta}_{\mathbf{v}}\end{array}$ & $\begin{array}{c}\boldsymbol{\delta}_{\mathbf{u}} \\
(\mathbf{m m})\end{array}$ & $\begin{array}{c}\boldsymbol{\mu} \\
=\boldsymbol{\delta}_{\mathbf{u}} / \boldsymbol{\delta}_{\mathbf{v}}\end{array}$ & enhancement \\
\hline BN-70 & 72.07 & 62.30 & 21.61 & 1.35 & 2.88 & 64.90 & 3.00 & - \\
\hline BC-70 & 71.28 & 64.42 & 22.58 & 1.41 & 2.85 & 69.70 & 3.09 & 2.78 \\
\hline BC-125 & 69.70 & 64.68 & 22.94 & 1.43 & 2.82 & 81.46 & 3.55 & 18.24 \\
\hline BK-125 & 72.60 & 65.47 & 22.92 & 1.43 & 2.86 & 76.64 & 3.34 & 11.34 \\
\hline
\end{tabular}




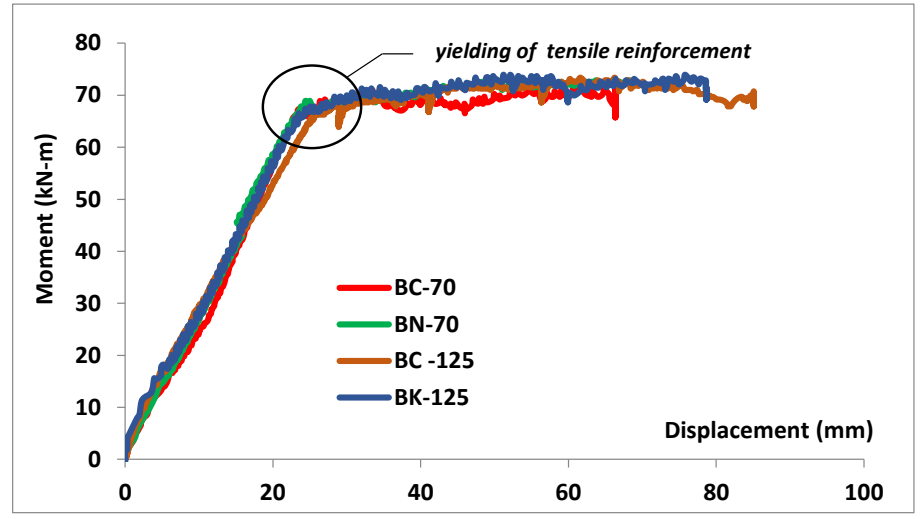

Fig. 4. Moment-displacement relationship on all four specimens

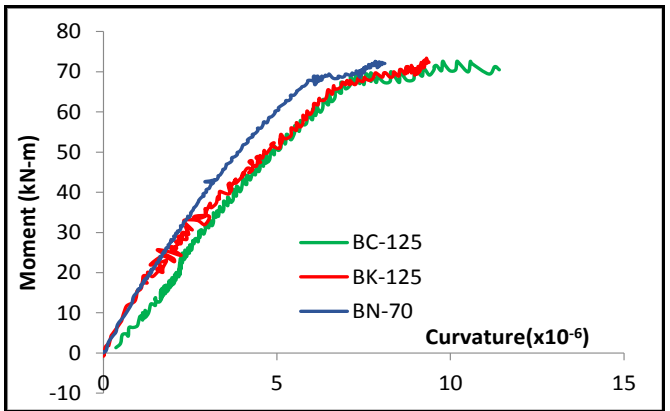

Fig. 5. Moment-curvature relationship

The test results showed that on the four specimens (BC-70, BN-70, BC-125, and BK-125) there was a dominant bending collapse pattern with the direction of the vertical crack upwards to the compression area. The heaviest damage occurred in accordance with the planned area of column face. No significant damage was found in the support or columns.

From Fig. 4 depicting the moment-displacement relationship of the four specimens in the middle of the beam span, it was seen that the four specimens have elastic stiffness curves which are the ratio of moment and displacement when the near yielding condition is approximately 2.8; while the value of Drift Ratio $(D R)$ at yield (which is the value of deviation per length) indicating that the presence of confinement in the compression zone of beam can increase the drift ratio of the beam and the addition of confinement spacing from $70 \mathrm{~mm}$ to $125 \mathrm{~mm}$ actually increases the drift ratio. The distance $125 \mathrm{~mm}$ is more effective than the confinement distance of $70 \mathrm{~mm}$. Having increased moment and displacement when yielding for the confinement of the beam, and the distance made wider than $70 \mathrm{~mm}$ to $125 \mathrm{~mm}$ does not significantly reduce the resulting moment. Although not yet the final result for the increase of ductility but it has been seen that spacing between confinement and wider stirrings is more effective for increasing the ductility of the beam as shown in Table 1 where the $125 \mathrm{~mm}$ spacing results in higher ductility compared to $70 \mathrm{~mm}$ distance which increases 11-18\% against the beam without confinement, whereas the interval $70 \mathrm{~mm}$ only increased by $2.78 \%$.

The test results show, although not yet reached the boundary condition seen that the change of distance from the confinement does not significantly affect the increase in the 
moment capacity that occurs. The increase in moments from yielding to near ultimate conditions only increased by about $1 \%$, which occurs either on hoops and crossties or on the beam without confinement. The test also shows the same moment level, the curvature of the beam with confinement in the compression zone is larger than the beam without confinement for either confinement hoops or crossties as shown in the fig. 5.

\section{Conclusion}

Based on the test results it can be concluded that the addition of the confinement from 70 $\mathrm{mm}$ to $125 \mathrm{~mm}$ on confinement in compression of beam indicates that the distance between confinement $125 \mathrm{~mm}$ more effectively increase the ductility and drift ratio of the beam compared to the distance of $70 \mathrm{~mm}$ and the beam without confinement. The difference in the distance between confinement from $70 \mathrm{~mm}$ to $125 \mathrm{~mm}$ is less significant affecting the change in moment capacity on the beam and for the same moment level, the presence of confinement in compression zone increases the curvature of the beam than the beam without confinement in both hoops confinement and crossties confinement.

Thank you to the Faculty of Engineering Diponegoro University through the Department of Civil Engineering for the Grant Assistance Basic Research which has been given to support this research.

\section{References}

1. O. Bayrak and S. A. Sheikh, Confinement Reinforcement Design Considerations for Ductile HSC Columns, ASCE Journal of Structural Engineering, V.124, No.9, p. 9991010 (1998)

2. O. Bayrak and S.A. Sheikh, Plastic Hinge Analysis, ASCE Journal of Structural Engineering, V.127, No.9, p. 1092-1100 (2001)

3. S. R. Razvi and M. Saatcioglu, Strength and Deformability of Confined High-Strength Concrete Columns, ACI Struct. Journal, V. 91, No. 6, p.678 - 686 (1994)

4. H. Tanaka and R. Park, Prediction of The Ultimate Longitudinal Compressive Concrete Strain at Hoop Fracture Using Energy Considerations, Library Niwa, ISSN: 0110-0718, p.290-305 (1987)

5. ACI Committee 318, Building Code Requirements for Structural Concrete (ACI 318 11) and Commentary, American Concrete Institute, Farmington Hills, Michigan, USA,p.503 (2011)

6. M. Saatcioglu and D. Baingo, Circular High Strength Concrete Columns Under Simulated Seismic Loading, ASCE Journal of Structural Engineering, V.125, No.3, p. 272-280 (1999)

7. SNI 2847-2013, Requirements for Structural Concrete Building in Indonesian. BSN (2013).

8. Y.A. Priastiwi, I. Imran, and Nuroji, The effect of different shapes of confinement in compression zone on beam's ductility subjected to monotonic loading, Procedia Eng. V125, p. 918-924 (2015). 